\title{
GLOBAL USE OF ANTIMICROBIALS IN FOOD ANIMALS, EMERGENCE OF ANTIMICROBIAL RESISTANCE AND WAY FORWARD: AN OVERVIEW
}

\author{
R. N. CHATTERJEE, S. S. PAUL* AND S.V. RAMA RAO \\ ICAR-Directorate of Poultry Research \\ Rajendranagar-500 030, Hyderabad, Telangana, India
}

\begin{abstract}
Several decades of antibiotic abuse in humans, animals and other farming systems and release of antimicrobials into environment from different sources are contributing to development of resistance to multiple classes of antibiotics in bacteria at a rate much faster than the rate at which newer antibiotics are being developed thus creating health emergency situation. Use of antibiotics as growth promoters (AGPs), wherein antibiotics are used at sub therapeutic dose for longer duration, favours selection and spread of resistant bacteria within animals and to humans through food or other environmental pathways. Expressed concerns are that AGPs are used to compensate for poor hygiene, health management and housing. Considering gravity of threat to human and animal health, some countries have banned use of AGPs while many countries are still using various antimicrobials as AGP including some of those categorized as important for human health. Recently many antibiotics being used in animals for therapeutic purpose are also being implicated for development of resistance. Different alternatives to AGPs are available but they may not be as cheaper as and also may not be as effective as antibiotics for improving survivability or performance of food animals reared under poor hygienic conditions or under environmental stress. Data on prevalence of antimicrobial resistance (AMR) is limited in India. There is urgent need to undertake detail study of prevalence of AMR and economic analysis of rearing food animals on various alternatives to antibiotics. Further, development of reliable certification system and higher pricing of animal products produced through alternate system and increasing consumer awareness can be a way forward to tackle the menace.
\end{abstract}

Key words: Alternatives to antibiotics, Antibiotic growth promoters, Antimicrobial resistance

Probably antibiotics have been around for millions of years as an outcome of mechanism of struggle for survival of microorganisms in hostile environment although scientific community came to know about their existence only in 1928 with discovery of the first antibiotic named as penicillin by Alexander Fleming and the research was formally published in the year 1929 (Fleming, 1929). Within four years of introduction of the first antibiotic penicillin for therapeutic use infections resistant to the drug began to appear. Emergence of antimicrobial resistance (AMR) is not unexpected considering that bacteria have been around for nearly four billion years and evolving in

*Corresponding Author 
very hostile environments, an essential characteristic for survival would have been the capacity to deal with harmful chemicals like antibiotics released by other bacteria and fungi (Rodríguez-Rojas et al., 2013; Blair et al., 2015). In a study, DNA isolated from 30,000-year-old permafrost cores, resistance genes to $\beta$-lactams, tetracycline and vancomycin were found (D'Costa et al., 2011). The 1940-1962 remained the golden era of antibiotic discovery. Many of the classes of antibiotics used today were discovered during this period. Presently only few newer antibiotics are under development. Unregulated use and misuse of antibiotics are giving rise to antibiotic resistance at faster rate than the rate at which newer antibiotics are being developed. Available reports have estimated a per annum human death toll of 23,000 in the USA, 25,000 in EU, and 58,000 in India from various drug resistant bacterial infections (Chaudhary, 2016). Thus emergence of antimicrobial resistance has become a global health challenge and major threat to human and animal health. AMR affects livestock productivity, impacting farmer livelihoods, food security and safety. In India, there is increasing evidence of resistance in human and animal pathogens to both older antimicrobials and newer critically important drugs like carbapenems (Kumaraswamy et al., 2010). Despite this, India has a paucity of reliable data on the quantities of, and drivers for antimicrobial use in humans and livestock production.

\section{Global use of antibiotics in food animals}

The amount of antimicrobials used in food animals has been estimated to escalate globally from 131,209 tons in 2013 to 200,235 tons by 2030 - an increase of $53 \%$ (Van Boeckel et al., 2017). The followings are the estimated global average annual consumption of antimicrobials to produce one kilogram of meat: $45 \mathrm{mg} / \mathrm{kg}$ beef, $148 \mathrm{mg} /$ $\mathrm{kg}$ chicken and $172 \mathrm{mg} / \mathrm{kg}$ pork (Van Boeckel et al., 2015). China, USA, Brazil, India and Germany utilize 23, 13, 9, 3 and 3 $\%$ of global antimicrobial use in food animal. In the USA $80 \%$ of annual antimicrobial consumption is in food animals. The use of antimicrobials in animal feed in India is projected to increase by $82 \%$ between 2010 and 2030 and their use in chicken is expected to triple between 2010 and 2030 (Van Boeckel et al., 2015). Tetracyclines accounted for the largest proportion of overall antimicrobial use globally (37.1\% of total), followed by polypeptides (15.7\%), penicillins $(9.8 \%)$, macrolides $(8.9 \%)$ and aminoglycosides (7.86\%) (OIE, 2019).

\section{Mechanism of development and spread of antimicrobial resistance}

Several mechanisms are known for effecting antimicrobial resistance including through efflux pumps, selective porin channels or inactivating enzymes, and to take rapid advantage of beneficial mutations in binding sites and cellular structures. Not all resistance mechanisms are found in all species of bacteria; particular resistance determinants are found in particular bacteria. For example, resistance to macrolides is determined by different mechanisms in campylobacter compared with those in staphylococci. When antibiotics are administered for more than 10 days, bacteria may become resistant to that antibiotic as well as other antibiotics. As an example, 2 days after the administration of tetracycline to chickens, tetracycline resistant $E$. coli can be isolated from fecal samples, and within 2 weeks, E. coli becomes resistant 
not only to tetracycline but also to multiple other drugs. Once the administration of antibiotics ceases, the loss of resistance is a slow process. Even after the antibiotic is removed from the environment, some bacteria populations can retain their antibiotic resistance for extended periods of time (Luo et al., 2005). Gene mutation that confers resistance to some of the antibiotics e.g. fluoroquinolone confers a fitness advantage to the pathogen in the absence of antibiotic pressure and hence the resistance gene is retained for much longer period (Luo et al., 2005). Resistance genes can spread through bacterial populations by different mechanisms like conjugal transfer of plasmids and other mobile genetic elements or by direct uptake of naked DNA (natural transformation) or by the action of bacteriophages (transduction).

Over time bacteria have been progressively resistant to multiple classes of antibiotics and they are called multi drug resistant (MDR) bacteria. Sometimes genes encoding resistance to one antibiotic in a class have the capacity to encode resistance to all antibiotics in that class and the phenomenon is called cross resistance. Another issue is co-selection for resistance (Cantón and Ruiz-Garbajosa, 2011). This occurs when multiple antibiotic resistance genes are located on a single plasmid or other mobile genetic element, so one of the co-located genes selects for resistance to all antibiotics on that plasmid or mobile genetic element. Generally it is accepted that the use of antimicrobials in human is the major driver of resistance development but, using antibiotics in animals also plays a role, though the data available to date are insufficient to quantify the contribution (Wall et al., 2016). Most bacteria and their genes can move relatively easily within and between humans, animals and the environment. Forslund et al. (2014) demonstrated that antibiotic use both in humans and in animals determines the resistance profile of bacteria in the human gut. The vast majority of antimicrobial classes are used both in humans and animals (including aquaculture; both farmed fish and shellfish). Only few antimicrobial classes are reserved exclusively for humans (e.g., carbapenems). There are also few classes limited to veterinary use (e.g., flavophospholipols, ionophores); mainly because of toxicity to humans. Insects (e.g., bees) and some plants are frequently treated with antimicrobials. Tetracyclines, streptomycin and some other antimicrobials are used for treatment and prophylaxis of bacterial infections of fruit, such as apples and pears.

In intensive animal farming and aquaculture, antimicrobials are often administered in sub therapeutic dose for prolonged period (two weeks and often almost the entire life of an animal, for example in chicken for 36 days or more) as growth promoter (FAO, 2018). These conditions favour selection and spread of resistant bacteria within animals and to humans through food or other environmental pathways.

Meat and egg from chickens reared under AGP may bear multidrug resistant zoonotic bacteria like Campylobacter, E.coli and Salmonella, and affect human health besides bearing AGP residues (Mehdi et al., 2018). Campylobacter is a major cause of food-borne diarrheal diseases in humans. According to CSCRA (2016) report, chicken contamination rates for E. coli, Campylobacter and Salmonella spp. are respectively 96\%, 25\% and 34\% in Canada. Antibiogram test revealed 
multi-pharmacological resistance in Enterobacteriaceae isolates from eggs and broiler meat (Diarra et al., 2010; Singh et al., 2010; Yulistiani et al., 2017). In one study on Salmonella enterica isolates collected from poultry farms in British Columbia (Canada), Diarra et al. (2014) showed that more than $43 \%$ of the isolates were simultaneously resistant to ampicillin, amoxicillin-clavulanic acid, ceftiofur, cefoxitim and ceftriaxone. Another Canadian study (Diarra and Malouin, 2014) highlights the existence of different stereotypes of Salmonella, isolated from broiler farms, resistant and multi-resistant to antibiotics.

Large amounts of antibiotics administered to animals are excreted into the environment via urine and faeces. After metabolic changes in animals, $30 \%$ to $90 \%$ of the dose consumed is found in the urine and feces as parent compounds and/or metabolite compounds (Carvalho and Santos, 2016). This makes sewage disposal systems one of the most important routes by which antibiotics can enter in the environment and contaminate even coastal waters (Chen et al., 2015). The aquatic environment is considered as an important point for acquisition and spread of antibiotic resistance genes by bacteria (Devarajan et al., 2017). The soil can also be contaminated by antibiotics in litter. Animal bedding contains residues of antimicrobial compounds. Residues of bacitracin, salinomycin, penicillin and virginiamycin were detected in chicken litter at concentrations ranging from 0.07 to $66 \mathrm{mg} / \mathrm{L}$ (Furtula et al., 2010). When this bedding material is used as nitrogen amendment, the resistant bacteria can live in the soil for several months (Merchant et al., 2012).
Antibiotic used in aquacultutre, apiculture and in plants or fruit crops, effluents from pharmaceutical industries and hospital waste are also being implicated for development of antimicrobial resistance.

Use of antibiotics in different ecosystem has led to environmental contamination (da Costa et al., 2013). Human sewage, livestock production, and aquaculture have all contributed to widespread distribution of antibiotic-resistant bacteria and genes in the environment (Abhirosh et al., 2011) facilitating their transmission to humans and animals.

\section{Global use of antibiotic growth promoters in livestock and poultry and their linkage with antimicrobial resistance}

Growth enhancement with antibiotics (sulphonamides) was first observed by Moore et al. (1946). The discovery by Jukes and his colleagues at Lederle Laboratories (Jukes, 1977) that aureomycin stimulated significant growth in chickens, cattle and pigs was the foundation of antibiotic growth promotion in animals.

About 40 percent of globally produced antibiotics are used as growth promoters (Hughes and Heritage, 2004). Antibiotic growth promoters (AGP) are commonly used in intensive cattle, pig and poultry farming to increase growth, improve feed efficiency and reduce disease incidence.

The use of antibiotics as animal growth promoters differs between countries. Sweden and UK now makes no use of antibiotics for growth promotion purposes (Begemann et al., 2018). The U.S. has removed all growth promotion clearances for medically important antibiotics from 2017, but allow use of ionophores and non-medically important 
prophylactic antibiotics (primarily bacitracin, avilamycin and bambermycins) (Smith, 2019). Virginiamycin was being used in different countries for prevention of lactic acidosis in cattle and as AGP in poultry, but use of this compound has led to the selection of bacteria that are resistant to its effects. It is related to pristinamicin and quinupristin, which are used in human medicine and so there are fears that its continued use may compromise human therapy. Its use as a growth promoter was banned in the EU. In 1995 vancomycin-resistant Enterococcus faecium was found in pigs and poultry that had been fed avoparcin-medicated feed (Bager et al., 1997). In 1996 the EU suspended the registration of avoparcin. Apart from avoparcin there were also concerns about tylosin in co-selecting for macrolide (eg erythromycin used in human) resistance and co-selecting for avoparcin resistance (Butaye et al., 1999). In 1999 EU suspended the use of tylosin, spiramycin, bacitracin and virginiamycin. By 2006 no AGPs remained registered in EU. Studies indicated that removing AGPs resulted in a substantial decline in antibiotic use (Millet and Maertens, 2011), had not increased the use of therapeutic antibiotics except in weaner pigs in Denmark (Grave et al., 2006) and had led to a decline in antibiotic resistance in enterococci isolated from animals and food (Wegener, 2003). In Australia the use of gentamicin is prohibited, fluoroquinolone use in food-producing animals has never been approved, use of 3rd generation cephalosporins is restricted and cefquinome has not been registered (APVMA, 2017). In India, Food Safety and Standards Authority of India issues advisory regarding limits of antibiotic residues in animal products for most of the commonly used antibiotics and
Ministry of Health and Family Welfare and Ministry of Fisheries, Animal Husbandry and Dairying has banned use of colistin and its formulations for food producing animals, poultry, aqua farming and animal feed supplements in 2019 (Anonymous, 2019).

\section{Antibiotics used for therapeutic purpose} in animals linked to antibiotic resistance Until quite recently only AGPs were being blamed for increased AMR instances. However, recently many antibiotics used in animals for therapeutic purpose are also being implicated for AMR. Enrofloxacin (a fluoroquinolone) was introduced in Europe and the USA in the late 1980s and resistance was first reported in veterinary isolates of Salmonella in the mid-1990s (Griggs et al., 1994). Subsequent studies have confirmed the use of fluoroquinolones in foodproducing animals to be a significant factor in the emergence of resistance in human infections (Moore et al., 2006; Nelson et al., 2007). Plasmid-borne fluoroquinolone resistance has now been found in animal isolates (de Jong et al., 2014; Yanat et al., 2017).

Ceftiofur, a 3rd generation cephalosporin, was introduced to the USA in 1998 and prior to that in Europe and strong links between the emergence of extended spectrum beta lactamases (ESBLs) mediated resistance to ceftriaxone in human and the use of ceftiofur (and cefquinome, which has been approved for use for some time in Europe but is not currently approved in the USA or Australia) in livestock has been recognized (Tyrrell et al., 2016). The enzymes that attack the 3rd and 4th generation cephalosporins such as ceftiofur and cefquinome respectively are 
now often referred to as Extended Spectrum Cephalosporinases (ESCs). There has been increase in the number of reports of ESCresistant organisms with the introduction of cefquinome, a 4th generation cephalosporin, onto the EU market for use in dairy cattle and horses. ESC activity has been reported in E.coli and Salmonella Enterobacteriaceae including Citrobacter spp., Klebsiella pneumoniae, Serratia spp. and Enterobacter cloacae as well as non-Enterobacteriaceae such as Acinetobacter (APVMA, 2017). Except E. Coli and Salmonella these organisms have largely been ignored in veterinary testing because most of them are not considered as animal pathogens and role of animals in the dissemination of such nonE.coli/Salmonella MDR organisms is slowly being revealed (Müller et al., 2014). However, antibiotic-resistant bacteria/genes could also be transferred from humans to animals (Schultz et al., 2015).

Resistant animal pathogens with multiresistance conjugative elements and multiresistance genes which encodes resistance to phenicols, lincosamides, oxazolidinones (such as linezolid), pleuromutilins and streptogramin A, were reported in staphylococci of animal origin and other Gram-positive bacteria and in enterococci and animal isolates of Gram-negative bacteria such as Proteus and E. coli (Shen et al., 2013; Tamang et al., 2017).

Currently carbapenemase-producing and colistin-resistant MDR Gram-negative bacteria have been on focus as carbapenems and colistin are antibiotics of last resort for infections caused by MDR Gram-negative bacteria (Al-Tawfiq et al., 2017; Madec et al., 2017).
Carbapenems are not registered for use in animals but resistance has been detected in livestock, seafood, horses and companion animals (Madec et al., 2017; Guerra et al., 2014). The most likely cause for this is coselection, though at first it was thought it might be the result of transfer from humans to animals or off-label or illegal use in animals (Falgenhauer et al., 2017). Most of the ESC-producing organisms are multidrug resistant and there are also reports of livestock and pet animals with ESC-resistant determinants on mobile plasmids (Seiffert et al., 2013).

Methicillin-resistant Staphylococcus aureus (MRSA) first emerged in the 1960s and became the most common nosocomial pathogen in hospital patients (Moellering, 2012). Subsequently, there were increasing reports of MRSA in different animals (Sun et al., 2015). The emergence of MRSA in humans led to introduction of vancomycin to treat resistant staphylococcal infections and this in turn led to the emergence of resistance to vancomycin.

\section{Mechanism of action of antibiotic growth promoters}

Healthy guts are essential to optimize digestibility in chicken. Intestinal epithelial cells are derived from cells situated in the intestinal crypt base. Cells proliferate by mitosis in the crypts, differentiating as they migrate upward to each villus and reach the villus tips, where they are shed into the intestinal lumen within 48 hours after birth (Potten, 1998). Generally fast growing broiler chicken are fed highly nutrient rich diets resulting in an excess of nutrients in the hindgut which causes the proliferation 
of harmful microbes (bacteria, fungi, protozoa, viruses ,etc) in the hindgut with the consequence disruption of gut microbiome-host equilibrium (Weiss and Hennet, 2017) causing the metabolic, pathogenic or sterile inflammation of gut (Kogut et al., 2018). Excess nutrients, especially protein and fat, are not well digested or absorbed which allows microbial proliferation in the ceca. With physiological retroperistalsis, these bacteria go back to the ileum and jejunum causing dysbacteriosis and even disease by the production of endo and exotoxins. Disturbances in the bacterial microbiota, due to this proliferation, result in dysregulation of adaptative immune cells and changes in microbial metabolism that can lead pathobiont microorganisms to become pathogens (Round and Mazmanian, 2009). AGPs have been the most consistent cost effective tool currently used to control dysbacteriosis and reducing microbial fermentation associated wastage of nutrients. Meta-genome sequencing approaches have demonstrated that different AGPs have different signature effects on gut microbiome. For example, populations of Lactobacillus spp. in the ileum of chickens receiving feed containing tylosin, a bacteriostatic, are significantly lower than those in chickens receiving no tylosin (Lin et al., 2013). The decrease in the Lactobacillus population in antibiotic-treated animals probably reduces the intestinal activity of the bile hydrolase salts, which would increase the relative abundance of conjugated bile salts, thus promotes lipid metabolism and energy harvesting and increases animal weight gain (Lin et al., 2013)

Besides suppressing sensitive populations of pathogenic or select non-pathogenic bacteria in the intestines thus reducing microbial fermentation associated wastage of nutrients in intestine and by reducing pathogen load and toxins, antibiotics are also believed to play important role by lowering need for immune response including cytokine release which lower the release of catabolic hormones and in turn muscle wastage, reducing intestinal bacterial (Lactobacillus and Bifidobacteria, etc.) bile salt hydrolase activity thus increasing fat digestion, lowering gut epithelial, turnover, inflammation and thickness leading to better absorption of nutrients and incidence of bacterial diseases especially under poor hygienic condition and under heat or humidity stress. Whatever the mechanism of action is, the production benefits of the use of antibiotic growth promoters ranges between 1 and 10 percent. Prescott and Baggot (1993), however, showed that the effects of growth promoters were much more noticeable in sick animals and those housed in cramped, unhygienic conditions. Surveillance and animal production data however now suggests that benefits in animals reared in good conditions are probably quite small and may be nonexistent.

\section{Antimicrobial resistance status in India and national action plan}

In 2017, the Centre for Science and the Environment, a non-profit organization based in New Delhi released a study entitled 'Antibiotic Resistance in Poultry Environment' (Bhushan et al., 2017). The study found that $100 \%$ of the E. coli, $92 \%$ of K. pneumoniae and $78 \%$ of S. lentus isolated from the poultry environment were multi-drug resistant. About $40 \%$ of E. coli and $30 \%$ of $K$. pneumoniae isolates were resistant to at 
least 10 out of 13 antibiotics against which these bacteria were tested for resistance. Both $E$. coli and $K$. pneumoniae had very high resistance to antibiotics such as penicillins, fluoroquinolones, third and fourth generation cephalosporins and carbapenems, which is a last resort antibiotic used in hospital.

As part of the 'National Programme for Containment of AMR' (2012-2017), it was decided to establish a laboratory based surveillance system by strengthening laboratories for AMR in the country and to generate quality data on antimicrobial resistance for pathogens of public health importance. The ICMR's Antimicrobial Resistance Surveillance and Research Network (AMRSN) is currently carrying out surveillance with a network of 16 laboratories across the country (Walia et al., 2019). A total of 30 labs in state medical colleges are planned to be strengthened in a phased manner to carry out surveillance. However, in the case of AMR in animals and food or antibiotics there is very limited surveillance. There are isolated studies, which have indicated high levels of AMR across animal commodities and systems, but they are yet to be unified under a nationally scaled programme. The Indian National Action Plan on AMR emphasizes a One Health approach.

In 2017, Indian health authorities released their National Action Plan on Antimicrobial Resistance (NAP-AMR) 2017-2021, that outlines the various challenges that need to be tackled to manage the phenomenon. There are six key areas that the NAP-AMR has identified as being strategic priorities for Indian health authorities to take action on. These include: Improved awareness of AMR through effective communication;
Strengthening knowledge and evidence through surveillance; Reducing the incidence of infection through effective infection prevention and control; Optimizing the use of antimicrobial agents in health, animals and food; Promoting investments for AMR activities, research and innovations; and Strengthening India's commitment and collaborations on AMR at international, national and sub-national levels.

\section{Strategies for reducing use of antibiotic growth promoters}

In developing countries like India antimicrobial growth promoters are often used to compensate for poor hygiene, housing and as replacement for proper animal health management. However, improvement in performance with AGP are in the range of $5-10 \%$ and such improvements are not very consistent and are largely limited to the period of high environmental stress. Keeping in view emerging threats of AMR for human and animal health, it has been advocated that use of antimicrobials as AGP should be banned. However, data on economic impact of such a blanket ban on Indian farmers has not been worked out. In the following section some of the strategies which are likely to contribute significantly in lowering use of AGPs in food animal rearing will be reviewed.

\section{Use of different alternatives to antibiotic growth promoters}

Research has been carried out to identify alternatives with similar beneficial effects of antibiotic growth promoters. Among these, the most popular are probiotics, prebiotics, enzymes, organic acids, immunostimulants, bacteriocins, bacteriophages, plant bioactive feed additives, phytoncides, nanoparticles 
and essential oils. Probiotics introduce desirable microorganisms into the gut. However, microbes used as probiotics are not exempted from acquiring antibiotic resistance genes. Given their shared microbial environment in the gastrointestinal tract, a risk of pathogenic microbes acquiring antibiotic resistance genes from probiotic microbes exists, and vice versa. Hence, probiotics need to be screened for antibiotic resistance (Imperial and Ibana, 2016). Prebiotics promote the growth of desirable bacteria in the gut whereas organic acids cause the inhibition of harmful bacterial growth (Dittoe et al., 2018). Enzymes such as phytases, carbohydrases and proteaes have been widely used due to their cost saving impact on diet formulation as productivity enhancers and also for their positive impact on gut microbiome. Exogenous enzymes reduce microbial proliferation by reducing the undigestable components of feed, phytate, the viscosity of digesta or the irritation to the gut mucosa that results in inflammation. Enzymes also generate metabolites that promote microbial diversity which helps to maintain gut ecosystems that are more stable and more likely to inhibit pathogen proliferation (Kiarie et al., 2013). The effects of plant bioactive compounds vary depending on their composition. They can be bacteriostatic or immune-stimulating. One category of plant bioactives are the essential oils (EO) or their active ingredients such as carvacrol, thymol, and cinnamaldehyde, etc., that have selective antimicrobial properties. The use of some specific EO blends has been shown to have efficacy towards reducing the colonization and proliferation of Clostridium perfringens and controlling coccidia infection and, consequently, may help to reduce necrotic enteritis (Oviedo-Rondón et al., 2010). Some evidence suggests that the combined administration of essential oils plus organic acids or prebiotics and probiotics might be the more effective than when used alone. Rearing chicken on these alternatives likely to be costlier than when raised on AGPs and performance may also be subpar.

\section{Improving water and feed quality}

Good water quality is also important for proper digestion and maintaining healthy gut. The $\mathrm{pH}$ of water should be maintained slightly acidic, between 5.5 and 7 , because basic water reduces the activity of most digestive enzymes. For this reason, drinking water with high levels of carbonates or other salts that increase the alkalinity and hardness can cause problems. High concentrations of salts and solids in the water and basic $\mathrm{pH}$ generally favor the production of biofilm and endotoxins in water lines and drinkers due to the proliferation of algae and microbes. Unhealthy gut due to poor water quality may increase use of antibiotic and promote antibiotic resistance. When the $\mathrm{pH}$ value of the crop is above 6.5 the enzyme activity can be reduced 10-15\% compared to the effectiveness observed at $\mathrm{pH}$ 4.5-5.5 (Kieroñczyk et al., 2016). Organic acids in feed or water create acidic conditions in the crop of broilers, but not in layers. Dietary calcium levels higher than the requirement for each age group and productive phase can be deleterious to intestinal health since it may chelate nutrients, reduce enzyme activity, and promote proliferation of Clostridium bacteria (Paiva et al., 2013).

Dietary fat for poultry should be free from rancidity. Diet should be free from mycotoxins. Quality control for soyabean meal is also important. Undercooked 
soybeans have higher antitrypsin factor concentrations whereas overcooking decreases protein digestibility.

\section{Improving bio security and hygiene and development of effective vaccines}

There is an urgent need to train farmers on bio security measures. Also there is urgent need to develop more effective vaccines against viral and bacterial diseases, which will go in the long way to reduce use of AGPs. Notably, in one study on 64 farms in 9 European countries, the majority of pig operations experienced cost reductions for antibiotic treatments after L. intracellularis vaccination, even though not all farms were able to reduce their antibiotic use (Adam, 2009). The development of new safe and effective adjuvants or the combination of vaccines with immune modulators may be a promising strategy for overcoming limitations in vaccine efficacy, in particular for relatively short-lived species such as poultry. In case of poultry, it has been suggested that development of new or improved vaccines for $E$ Coli, infectious

\section{REFERENCES}

Anonymous, 2019. 2019.07.19 S.O. 2607 Prohibition of Colistin for food producing animals, poultry, aqua farming and animal feed supplements under Sec.26A. https:// cdsco.gov.in/opencms/opencms/en/ Notifications/Gazette-Notifications/

Abhirosh C, Sherin V, Thomas A, Hatha A and Mazumder A, 2011. Potential public health significance of faecal contamination and multidrug-resistant Escherichia coli and Salmonella serotypes in a lake in India. Public Health, 125: 377-379

Adam M, 2009. A meta-analysis on field bursal disease virus, Clostridium perfringens type A, Eimeria and infectious bronchitis virus may reduce antibiotic use dramatically (Hoelzer et al., 2018)

Bans on growth promoters within Europe led to little or no impact on livestock productivity and disease, including in poultry, yet changes in the management of farms such as improvements in hygiene and biosecurity, and associated costs are not available in public domain. These results are based on European production systems with high levels of bio security, and are difficult to extrapolate to current antimicrobial use and potential impacts of change in antimicrobial use on AMR and livestock feed systems in India. There is urgent need to undertake detail study and economic analysis of various alternatives to antibiotics before farmers can be pursued to do away with AGPs. Further, development of reliable certification system and higher pricing of poultry products produced through alternate system and increasing consumer awareness can be a way forward.

experiences with vaccination against Ileitis showing a reduction on antibiotics use. In: safe Pork conference proceedings, Quebec, Canada, pp3303, http://lib.dr.iastate.edu/ safepork/2009 44

Al-Tawfiq JA, Laxminarayan R and Mendelson M 2017. How should we respond to the emergence of plasmid-mediated colistin resistance in humans and animals? Int $\mathrm{J}$ Infect Dis, 54: 77-84

APVMA, 2017. Antibiotic resistance in animals-A report for the. Australian Pesticides and Veterinary Medicines Authority (APVMA). Kingston ACT 2604 Australia pp1-48 
Bager F, Madsen M, Christensen J and Aarestrup F, 1997. Avoparcin used as a growth promoter is associated with the occurrence of vancomycinresistant Enterococcus faecium on Danish poultry and pig farms. Prev Vet Med, 31: 85112

Begemann S, Perkins E, Van Hoyweghen I, Christley $\mathrm{R}$ and Watkins F, 2018. How political cultures produce different antibiotic policies in agriculture: a historical comparative case study between the United Kingdom and Sweden. Sociol Ruralis, 58: 765-785

Bhushan C, Khurana A, Sinha R and Nagaraju M, 2017. Antibiotic resistance in poultry environment: spread of resistance from poultry farm to agricultural field, centre for science and environment, New Delhi. Available online:http://www.cseindia.org/userfiles/ Antibioticspercent 20 n percent 20 Chickenpercent 2030 percent20july.pdf

Blair J, Webber M, Baylay A, Ogbolu D and Piddock L. 2015. Molecular mechanisms of antibiotic resistance. Nat Rev Microbiol, 13: $42-51$

Butaye P, Devriese L and Haesebrouck F, 1999. Phenotypic distinction in Enterococcus faecium and Enterococcus faecalis strains between susceptibility and resistance to growth-enhancing antibiotics. Antimicrob Agents Chemother, 43: 2569-2570

Cantón R and Ruiz-Garbajosa P, 2011. Coresistance: An opportunity for the bacteria and resistance genes. Curr Opin Pharmacol, 11: 477-485

Carvalho IT and Santos L, 2016. Antibiotics in the aquatic environments: A review of the European scenario. Environ Int, 94: 736e57

Chaudhary AS, 2016. A review of global initiatives to fight antibiotic resistance and recent antibiotics' discovery. Acta Pharmaceutica Sinica B, 6: 552-556

Chen H, Liu S, Xu XR, Zhou GJ, Liu SS et al., 2015. Antibiotics in the coastal environment of the hailing bay region, south China sea: spatial distribution, source analysis and ecological risks. Mar Pollut Bull, 95: 365e73

CSCRA, 2016. Syst_eme canadien de surveillance de la r_esistance aux antimicrobiens e rapport De 2016. Gouvernement du Canada.

da Costa P, Loureiro L and Matos A, 2013. Transfer of multidrug-resistant bacteria between intermingled ecological niches: the interface between humans, animals and the environment, Int J Environ Res Public Health, 10: $278-294$

D’Costa V, King C, Kalan L, Morar M, Sung W et al., 2011. Antibiotic resistance is ancient, Nature, 477: 457-461

de Jong A, Smet A, Ludwig C, Stephan B, De Graef E et al., 2014. Antimicrobial susceptibility of Salmonella isolates from healthy pigs and chickens (2008-2011). Vet Microbiol, 171: 298-306

Devarajan N, Kohler T, Sivalingam P, van Delden C, Mulaji CK et al., 2017. Antibiotic resistant Pseudomonas spp. In the aquatic environment: a prevalence study under tropical and temperate climate conditions. Water Res, 115: 256e65

Diarra MS and Malouin F, 2014. Antibiotics in Canadian poultry productions and anticipated alternatives. Front Microbiol, 5: 282-289

Diarra MS, Rempel H, Champagne J, Masson L, Pritchard J et al., 2010. Distribution of antimicrobial resistance and virulence genes in Enterococcus spp. and characterization of isolates from broiler chickens. Appl Environ Microbiol, 76: 8033e43

Diarra MS, Delaquis P, Rempel H, Bach S, Harlton C et al., 2014. Antibiotic resistance and diversity of Salmonella enterica serovars associated with broiler chickens. J Food Protection, 77: 40-49

Dittoe DK, Ricke SC and Kiess AS, 2018. Organic acids and potential for modifying the avian 
gastrointestinal tract and reducing pathogens and disease. Front Vet Sci, 6(5): 216, doi: 10.3389/fvets. 2018.00216 . PMID: 30238011; PMCID: PMC6136276

Food and Agriculture Organization (FAO), 2018. World Health Organization (WHO). FAO/ WHO Expert Meeting on Foodborne Antimicrobial Resistance: Role of Environment, Crops and Biocides. Summary Report; FAO: Rome, Italy. http://www.fao.org/ 3/CA0963EN/ ca0963en.pdf

Falgenhauer L, Ghosh H, Guerra B, Yao Y, Fritzenwanker $\mathrm{M}$ et al., 2017. Comparative genome analysis of IncHI2 VIM-1 carbapenemase-encoding plasmids of Escherichia coli and Salmonella enterica isolated from a livestock farm in Germany. Vet Microbiol, 200: 114-117

Fleming A, 1929. On the antibacterial action of cultures of a penicillium, with special reference to their use in the isolation of $B$. Influenza. Br J Exp Pathol, 10: 226-236

Forslund K, Sunagawa S, Coelho LP and Bork P, 2014. Metagenomic insights into the human gut resistome and the forces that shape it. Bioessays, 36: 316-329

Furtula V, Farrell EG, Diarrassouba F, Rempel H, Pritchard J et al., 2010. Veterinary pharmaceuticals and antibiotic resistance of Escherichia Coli isolates in poultry litter from commercial farms and controlled feeding trials. Poult Sci, 89: 180e8

Grave K, Jensen VF, Odensvik K, Wierup M and Bangen M, 2006. Usage of veterinary therapeutic antimicrobials in Denmark, Norway and Sweden following termination of antimicrobial growth promoter use. Prev Vet Med, 75: 123-132

Griggs D, Hall M, Jin Y and Piddock L, 1994. Quinolone resistance in veterinary isolates of Salmonella. Antimicrob Agents Chemother, 33: 1173-1189

Guerra B, Fischer J and Helmuth R, 2014. An emerging public health problem: acquired carbapenemase-producing microorganisms are present in food-producing animals, their environment, companion animals and wild birds. Vet Microbiol, 171: 290-297

Hoelzer K, Bielke L, Blake DP, Cox E, Cutting SM, et al., 2018. Vaccines as alternatives to antibiotics for food producing animals. Part 1: challenges and needs. Vet Res, 49: 64

Hughes P and Heritage J, 2004. Antibiotic growthpromoters in food animals. In assessing quality and safety of animal feeds. FAO, Rome, Italy, pp129-151, http:// www.fao.org/tempref/docrep/fao/007/ y5159e/ y5159e05.pdf

Imperial ICVJ and Ibana JA, 2016. Addressing the antibiotic resistance problem with probiotics: reducing the risk of its double-edged sword effect. Front Microbiol, 7: 1983, doi:10.3389/ fmicb.2016.01983

Jukes TH, 1977. The history of the "antibiotic growth effect." Fed Proc, 37: 2514-2518

Kiarie E, Romero LF and Nyachoti CM, 2013. The role of added feed enzymes in promoting gut health in swine and poultry. Nutr Res Rev, 26: $71-88$

Kieroñczyk B, Rawski M, Długosz J, Swiạtkiewicz S and Józefiak D, 2016. Avian crop function - A review. Ann Anim Sci, 16: 653-678

Kogut MH, Genovese KJ, Swaggerty CL, He H and Broom L, 2018. Inflammatory phenotypes in the intestine of poultry: not all inflammation is created equal. Poult Sci, 97: 2339-2346

Kumaraswamy KK, Toleman AA, Walsh TR, Bagaria J, Butt F et al., 2010. Emergence of a new antibiotic resistance mechanism in India, Pakistan, and the UK: a molecular, biological, and epidemiological study. Lancet Infect Dis, 10: $597-602$

Lin J, Hunkapiller AA, Layton AC, Chang YJ and Robbins KR, 2013. Response of intestinal microbiota to antibiotic growth promoters in 
chickens. Foodb Pathog Dis, 10: $331 \mathrm{e} 7$

Luo N, Pereira S, Sahin O, Lin J, Huang S et al., 2005. Enhanced in vivo fitness of fluoroquinolone-resistant Campylobacter jejuni in the absence of antibiotic selection pressure. Proceed Nat Acad Sci, 102: 541-546

Madec JY, Haenni M, Nordmann P and Poirel L, 2017. Extended-spectrum â-lactamase/ AmpC- and carbapenemase-producing Enterobacteriaceae in animals: a threat for humans?, Clin Microbiol Infect, 23(11): 826833

Mehdi Y, Letourneau-Montminy MP, Gaucher ML, Chorfi Y, Suresh G et al., 2018. Use of antibiotics in broiler production: Global impacts and alternatives. Anim Nutr, 4: 170178

Merchant LE, Rempel H, Forge T, Kannangara T, Bittman S et al., 2012. Characterization of antibiotic-resistant and potentially pathogenic Escherichia coli from soil fertilized with litter of broiler chickens fed antimicrobial supplemented diets. Can J Microbiol, 58: 1084e98

Millet S and Maertens L, 2011. The European ban on antibiotic growth promoters in animal feed: from challenges to opportunities. Vet J, 187: $143-144$

Moellering R, 2012. MRSA: the first half century, J Antimicrob Chemother, 67: 4-11

Moore J, Barton M, Blair I, Corcoran D, Dooley J et al., 2006, The epidemiology of antibiotic resistance in Campylobacter. Microbes Infect, 8: $1955-1966$

Moore PR, Evension A, Luckey TD, McCoy E, Elvehjem CA et al., 1946. Use of sulfasuxidine, stretothricin and streptomysin in nutritional studies with the chick. J Biochem, 165: 437-441

Müller S, Janssen T and Wieler L, 2014. Multidrug resistant Acinetobacter baumannii in veterinary medicine-emergence of an underestimated pathogen?, Berl Munch
Tierarztl Wochenschr, 127: 435-446

Nelson J, Chiller T, Powers J and Angulo F, 2007. Fluoroquinolone-resistant Campylobacter species and the withdrawal of fluoroquinolones from use in poultry: a public health success story. Clin Infect Dis, 44: 977980

OIE, 2019. World Organisation for Animal Health (OIE). OIE Annual Report on Antimicrobial Agents Intended for Use in Animals. Second Report; OIE: Paris, France, 2018. online:http:/ /www.oie.int/fileadmin/Home/ eng/ Our_scientific_expertise/docs/pdf/AMR/ Annual_Report_AMR_2.pdf (accessed on 15 January 2019)

Oviedo-Rondón EO, Hume ME, Barbosa NA, Sakomura NK, Weber G et al., 2010. Ileal and cecal microbial populations in broilers given specific essential oil blends and probiotics in two consecutive grow-outs. Avian Res, 3: 157169

Paiva DM, Walk CL and McElroy AP, 2013. Influence of dietary calcium level, calcium source, and phytase on bird performance and mineral digestibility during a natural necrotic enteritis episode. Poult Sci, 92: 3125-3133

Potten CS, 1998. Stem cells in the gastrointestinal epithelium: numbers, characteristics and death. Philos Trans R Soc Lond B Biol Sci, 353(1370): 821-830

Prescott JF and Baggot JD 1993. Antimicrobial Therapy in Veterinary Medicine, $2^{\text {nd }}$ edn., Iowa State University Press, pp564-565

Rodríguez-Rojas A, Rodríguez-Beltrán J, Couce A and Blázquez J, 2013. Antibiotics and antibiotic resistance: A bitter fight against evolution. Int J Med Microbiol, 303: 293-297

Round JL and Mazmanian SK, 2009. The gut microbiota shapes intestinal immune responses during health and disease. Nat Rev Immunol, 9: 313-323

Schultz E, Haenni M, Mereghetti L, Siebor E, Neuwirth C et al., 2015. Survey of multidrug 
resistance integrative mobilizable elements SGI1 and PGI1 in Proteus mirabilis in humans and dogs in France, 2010-13. J Antimicrob Chemother, 70: 2543-2546

Seiffert S, Hilty M, Perreten V and Endimiani A, 2013. Extended-spectrum cephalosporinresistant Gram-negative organisms in livestock: an emerging problem for human health?, Drug Resist Updat, 16: 22-45

Shen J, Wang Y and Schwarz S, 2013. Presence and dissemination of the multiresistance gene $\mathrm{cfr}$ in Gram-positive and Gram-negative bacteria. J Antimicrob Chemother, 68: 1697-1706

Singh S, Yadav AS, Singh SM and Bharti P, 2010. Prevalence of salmonella in chicken eggs collected from poultry farms and marketing channels and their antimicrobial resistance. Food Res Int, 43: 2027e30

Smith JA, 2019. Broiler production without antibiotics: United States field perspectives. Anim feed Sci Technol, 250: 93-98

Sun J, Yang M, Sreevatsan S and Davies PR, 2015. Prevalence and characterization of Staphylococcus aureus in growing pigs in the USA. PLoS One, 10(11): e0143670, doi: 10.1371/journal.pone.0143670. eCollection 2015

Tamang MD, Moon DC, Kim SR, Kang HY, Lee K et al., 2017. Detection of novel oxazolidinone and phenicol resistance gene optrA in enterococcal isolates from food animals and animal carcasses, Vet Microbiol, 201: 252256

Tyrrell, JM, Wootton, M, Toleman, MA, Howe, RA, Woodward $\mathrm{M}$ et al., 2016. Genetic and virulence profiling of ESBL-positive E. coli from nosocomial \& veterinary sources. Vet Microbiol, 186: 37-43

Van Boeckel T, Brower C, Gilbert M, Grenfell B,
Levin S et al., 2015. Global trends in antimicrobial use in food animals. Proc Natl Acad Sci USA, 112: 5649-5654

Van Boeckel T, Glennon E, Chen D, Gilbert M, Robinson TP et al., 2017. Reducing antimicrobial use in food animals. Science, 357: $1350-1352$

Wall BA, Mateus A, Marshall L, Pfeiffer DU, Lubroth J et al., 2016. Drivers, dynamics and epidemiology of antimicrobial resistance in animal production, FAO Rome, available at http://www.fao.org/documents/ card/en/c/ d5f6d40d-ef08-4fcc-866b-5e5a92a12dbf/

Walia K, Madhumathi J, Veeraraghavan B, Chakrabarti A, Kapil A et al., 2019. Establishing antimicrobial resistance surveillance and research network in India: Journey so far. The Indian J Med Res, 149: 164-179

Wegener H, 2003. Antibiotics in animal feed and their role in resistance development. Curr Opin Microbiol, 6: 439-445

Weiss A and Hennet T, 2017. Mechanisms and consequences of intestinal dysbiosis. Cell Mol Life Sci, 74: 2959-2977

Yanat B, Rodríguez-Martínez JM and Touati A, 2017. Plasmid-mediated quinolone resistance in Enterobacteriaceae: a systematic review with a focus on Mediterranean countries. Eur J Clin Microbiol Infect Dis, 36: 421-435

Yulistiani R, Praseptiangga D, Supyani, Sudibya, Raharjo D et al., 2017. Prevalence of antibiotic resistance Enterobacteriaceae strains isolated from chicken meat at traditional markets in Surabaya, Indonesia. IOP Conference Series: Materials Science and Engineering, 193: 012007, doi:10.1088/1757-899X/193/1/ 012007

Article received on 12.10 .2019 and accepted for publication on 16.11.2019 